\title{
Contrapunto de un viaje de ida y vuelta: Israel y Venezuela de 1987 a 2012
}

\author{
Laura M. FEBRES \\ Universidad Metropolitana \\ lfebres@unimet.edu.ve
}

\begin{abstract}
Resumen:
En este trabajo analizaremos dos momentos distintos en el relato femenino que se ha generado entre la comunidad Israelí y Venezuela. Como muestra del primero de ellos, analizaremos la novela Cláper de Alicia Freilich (1987) donde la autora narra la llegada de su padre a tierras venezolanas proveniente de Léndov en Polonia. El padre llega solo, pero luego construye una familia que vive distintas épocas de Venezuela, desde la dictadura de Juan Vicente Gómez hasta la irrupción de la llamada época de las guerrillas en el panorama nacional de los años sesenta. La novela es narrada por su hija, la cual a pesar de la escasa instrucción de sus progenitores, puede acceder a la universidad, haciendo caso omiso de las advertencias del padre con respecto a la senda a la cual esta educación podría conducirla.

El estudio de esta primera novela tiene el mérito de develar la intimidad de una familia, donde observamos el trato responsable del padre hacia su esposa e hijos, como no ocurre en otras novelas en las cuales las mujeres son maltratadas incluso por aquellos que se autodenominan liberales.

El segundo relato se encuentra en el libro Pasaje de Ida (2012) compilado por la escritora Silda Cordoliani, en el cual Liliana Lara expresa en un relato parecido a una fotografía instantánea, sus vivencias en Israel; país al que ha emigrado recientemente. También en él nos pinta las peripecias de una familia que se tiene que adaptar a una nueva forma de vida donde el lenguaje tiene un papel fundamental.
\end{abstract}

Palabras clave: Relato; Siglos XX y XXI; Venezuela; Israel.

\section{A round-trip contrast: Israel and Venezuela from 1987 to 2012.}

\begin{abstract}
:
In the following work, we will describe two different moments of the female story that has been generated between the Israeli and Venezuelan communities. As a proof of that, we will analyze the novel Cláper by Alicia Freilich (1987) in which the author narrates the arrival of her father to Venezuelan soil coming from Léndov, Poland. At first, the father lives alone, but then he raises a family that lives throughout different historic times of Venezuela, from the dictatorship of Juan Vicente Gómez to the sudden appearance of the guerrillas in the national panorama. The novel is narrated by the daughter, who despite the lack of instruction of her parents, is able to attend university disobeying her father's warnings of not following the way to which that education could lead her.

The study of this first novel holds the merit of revealing the intimacy of a family in which we can observe the father's responsible behavior to his wife and children in contrast to other novels where the women are physically abused even by those who call themselves "liberals".

The second story can be found in the book Pasaje de Ida (2012) compiled by the writer Silda Cordoliani in which the Venezuelan writer Liliana Lara expresses in a photography-like story her experiences in Israel, a country where she has recently emigrated. It is also possible to read about all the setbacks of a family that has to adapt to a new lifestyle.
\end{abstract}

Key words: story; 20th and 21st centuries; Venezuela; Israel. 


\section{Referencia normalizada:}

Febres, L. M. (2014): Contrapunto de un viaje de ida y vuelta: Israel y Venezuela de 1987 a 2012 . Historia y Comunicación Social. Vol. 19. Núm. Especial Enero. Págs. 291-302.

Sumario: 1.Introducción. 2. Metodología. 3 Dos espacios narrativos en Claper. 4 El relato de un padre. 5 Las confesiones de una hija. 6 El regreso a Israel en dislocaciones de Liliana Lara. 7 Conclusión. 8. Referencias bibliográficas.

Hablo un idioma moldeado en gran parte por mis hijos.(Lara en Cordoliani, 2013: 90)

\section{Introducción}

En el grupo de investigación "La Mirada femenina desde la diversidad cultural" de la Universidad Metropolitana, venimos estudiando los relatos que escriben las mujeres como testimonio de su experiencia migratoria desde el año 2006.

Cada relato expone una vivencia femenina distinta que es expresión de las culturas que entran en contacto.

En el caso nuestro hemos estudiado la emigración de las judías de distintas partes del mundo a tierras americanas. Para ello hemos contado con el análisis que hacen diferentes fuentes sobre la cuestión de la mujer en el judaísmo como el libro $E l$ judaísmo y la mujer publicado en Buenos Aires por la Fundación Alianza Cultural Hebrea. Centrado más en nuestra temática en tierras americanas, hemos revisado los distintos capítulos de novela contenidas en el libro titulado: The House of Memory: Stories by Jewish Women Writers of Latin America realizado por Marjorie Agosin.

También hemos realizado un trabajo previo Importancia del árbol familiar en la diáspora judía a través de las novelas latinoamericanas: Perfumes de Cartago de Teresa Porzecanski (1994) y Las Mujeres de Houdini de Sonia Chocrón (2012) donde analizamos la adaptación de la mujer judía al Uruguay y Venezuela.

Hablamos de la nueva identidad que se crea la mujer judía, la cual tiene como raíz fundamental el árbol familiar que se construye junto con la exploración de las vicisitudes que tuvieron que pasar sus antepasados en Oran, Siria y el mar Mediterráneo, para luego venir a construir una familia en tierras tan disímiles.

Sin embargo, aquí abordaremos la novela Claper el marchante en su cuarta edición que habla de la adaptación de otra familia judía a la sociedad venezolana y de una temática nueva, la adaptación de una venezolana a la sociedad israelí titulada Dislocaciones, escrita por Liliana Lara y compilada en el libro Pasaje de ida por la escritora Silda Cordoliani.

En ambos relatos la preocupación por explicar el hecho literario que se traduce en la lengua del escritor es patente, aunque expresado en dos formas distintas, una novela y un pequeño testimonio. 


\section{Metodología}

Hacemos en este trabajo un estudio detallado de dos relatos de escritoras cercanas a la sociedad israelí, donde se expresan la adaptación a dos países en aras de investigar cómo el proceso de inmigración de las familias judías a tierras venezolanas, se ha revertido y ahora son las venezolanas las que emigran al Estado de Israel.

En la primera novela estudiada la estructura de la obra combina el relato del padre, un escritor que habla acerca de su búsqueda de nuevas tierra para establecerse, con el relato de la hija que ingresa a la Universidad donde pasará cuatro años de su vida.

Los adioses formulados por los dos personajes al espacio dejado atrás, se confunden por su semejanza. El padre dice en Léndov:

“Adiós papá y mamá, que no sepan de males. Sin despedirse, sin besos ni abrazos, su hijo se marcha pero no los deja ..." (Freilich, 2008:12)

La hija dice en Caracas, cuando va a la Universidad: "Adiós mis medievales papi y mami, al fin soy una libre pajarita" Freilich (2008:13)

La estructura del segundo relato es una corta confesión de la autora acerca de su experiencia de adaptación en la tierra israelí, pero también se nota que está muy unida a su familia como veremos más adelante.

\section{Dos espacios narrativos en claper}

Esta novela tiene la intención de captar dos épocas históricas, la del padre que expresa las vicisitudes que sufrieron los judíos en Europa, cuando eran discriminados indistintamente por los polacos, alemanes y franceses y la de la hija, que incluso tiene un estilo de letra distinto al del padre dentro de la novela. Ambos se constituyen en dos narradores distintos dentro del relato. La hija nos cuenta:

Hace medio siglo comenzó a llegar a estas tierras, un grupo de musiúes que tocaba puertas para vender trapos. Llamaban. Clap, clan, clan, como decir en criollo tun, tun. Ellos mismos escogieron la palabra cláper para definirse. Pues bien, hija de cláper, también soy una llamadora, ... Siento que el país actual es aquel don Fulgencio, el eterno adulto infantil porque no tuvo infancia. Adolece de un don muy preciado y fundamental para crecer con madurez. ¿Cuál? La aspiración por realizarse uno en el trabajo que le gusta y su derivado inmediato, la felicidad por el logro...ंentienden? - ¡Sería excelente en una asesoría de Educación...!-Necesitamos pensadores en la dirigencia de mi organización ideológica, ¡véngase y tendrá chofer en la puerta sin necesidad de marcar tarjeta!

No gracias. Sería pésima como profesional de la política. Carece de talento, paciencia y capacidad para urdir intrigas. Freilich (2008:145)

El relato del padre está escrito en la letra constante de la novela. Ambos padre e hija comparten el gusto por el periodismo, aunque su visión de los hechos narrados, 
sea totalmente distinta y en ciertas ocasiones entren en conflicto. Oigamos la voz del padre:

Me gusta mucho redactar ese bendito manojo de palabras cada mes porque el comercio te vuelve rey pero quita sosiego y te aleja del ocio amable. Era difícil repartirse. Comprar y vender junto con lectura y pensar para escribir, es una mezcla de agua y aceite. Freilich (2008:146)

Ellos comunican al público sus ideas sobre la historia en que viven, que luego se vuelve memoria trastocada por el paso del tiempo. Ambos relatos tienen una fuerte carga irónica. Esto proviene del análisis de situaciones que chocan entre sí cuando son expresadas en contextos culturales diferentes y provocan la sonrisa constante del lector:

Primero, en la casa de San José y luego en San Leopoldino, cuanto escritor, conferencista, delegado y visitante pasaba por Caracas, era comensal obligado en el modesto y pequeño apartamento del edificio Nuestra Señora del Carmen, título contradictorio para albergar una gente de tradiciones tan nuestras como aquélla. Más de un invitado llegó a señalarlo con ironía sin lograr que los anfitriones se molestaran. Freilich (2008:19)

\section{El relato de un padre}

La novela esta dedicada a la voz del padre, Mordejai, "o Max como me llaman aquí" Freilich (2008:195), que viene a fundar una familia en tierras americanas. La narradora hace un homenaje a este personaje, relatando las peripecias que tuvo que sufrir para conseguir una posición estable en el nuevo país.

Antes de llegar a él la primera vez, toca tierras cubanas en las que permanece por un corto tiempo, de donde huye por el clima de inseguridad que se respira durante el gobierno de Gerardo Machado (1925-1933).

Max se une a un grupo socialista, que debido a su ideología teme por las vidas de sus integrantes. En Polonia ya había pertenecido al "partido socialista-sionista Poalé Zión" aunque no formó "parte del grupo que luego siguió las órdenes comunistas." Freilich (2008:68)

El padre es sumamente religioso. Mientras está en tierras europeas todo lo que pasa se lo atribuye a la voluntad divina:

Me subieron al auto policial rumbo a la estación y bañado en sudores de felicidad salí en un milagroso tren germano que me conseguiste en verdad tú, el de nombre bendito y de quien cada minuto que pasa, soy menos digno. Si te llevo en mi corazón, dime, ¿para qué perder tiempo buscándote por los cielos, ah, diosito lindo? Freilich (2008:40) 
Al enterarse de la muerte de sus padres, Max regresa a Polonia cuando está a punto de estallar la Segunda Guerra Mundial y escucha de su hermana el relato de sus últimos días:

A la fuerza me los traje a Varsovia. Si los dejaba en Léndov, pronto mi padre tendría que cargar sobre sus espaldas alguna mudanza para conseguir los tres céntimos del escaso alimento que ellos consumían...-Destrozarles primero la moral, luego el organismo, eso querían hacer de ellos...-Aquí se fueron apagando rápido como una planta sin sol ni agua, fuera de su medio natural, uno tras otro, en cinco meses, ya sabes ... y empezaron a bendecir el minuto en que te fuiste... Freilich (2008:182)

Max intenta convencer a su hermana para que salga de Varsovia, pero esta se resiste a dejar la hermosa ciudad en que vivía que pronto se convertirá en cenizas:

Se pusieron muy orgullosos con tu última carta donde contabas que eras periodista y lloraron con tus artículos...-¿No los sacaste de Léndov para evitar que se murieran de hambre? ¿Qué esperas tú? ¿Cuánto falta para que pierdas el empleo? No me cambies el tema y contesta. -Es distinto. Eran ancianos. - ¿Ancianos de cincuenta años? -Sí, eran Cálmate. Esta es una tempestad pasajera. Ves tinieblas dónde sólo hay penumbra... Freilich (2008:182)

La desolación que ve Max en los pueblos de Centro Europa producto del próximo estallido de la guerra lo hace escribir lo siguiente:

Lo que veo ¿es miseria? Pobres fuimos siempre, casi todos. Aquí hay otra cosa. Un odio calculado para arruinar el amor propio. No les quitan el pan sino la posibilidad de ganarlo. ...

¡Dios Mío! La calamidad es ciega, ¡pero tiene un talento especial para localizarnos siempre! ...

¡Ay de ti Polonia! ¡Quien cierra sus manos a la compasión y sus oídos al llanto del pobre, algún día llamará y no será escuchado! Freilich (2008:173)

Conoce en este segundo viaje a Ryfka, su esposa, que lo acompañará toda su vida y sobre ella comenta:

Al oro se lo prueba con fuego y a la mujer con el oro ....Ryfka es modesta y estudia Contabilidad en una escuela dirigida por su pariente Broslavski. Buena Carrera, pienso. Porque esposo y esposa son una sola carne pero la separan cuando tienen diferentes bolsillos. Una mujer que sabe contar bien sería adecuada para un marido que sólo sabe perder... Freilich (2008:170)

Sin embargo esta no es la opinión de la familia de su mujer, quienes piensan lo siguiente:

Les parezco muy mal candidato pues me consideran un trotamundos ateo, aventurero en tierras lejanas, un hombre al aire cuya vestimenta de colores atrevidos es un reto a dios. Y lo peor, un loco listo para devolverse a cierto país bárbaro donde los indios se comen vivos a los blancos... Freilich (2008:185) 
Cuando regresa a Venezuela, ya casado, Max es el árbitro en su casa de los pleitos que ocurren dentro de la comunidad judía, dice que tiene el título de "embajador comunitario sin sueldo" Freilich (2008:144) en Caracas y continúa en esta ciudad con su fuerte interpretación religiosa de la historia, que se evidencia en la conversación entre padre e hija:

El triunfo de Rómulo Betancourt es justicia de Dios.-¿Quieres decir que al fin llegó el Mesías?-Mejor que eso. Ocurrió lo justo y conveniente porque ese hombre viene combatiendo contra el comunismo desde antes que murió Gómez y es un tipo que sí sabe como enfrentarlos...- ¿A cuáles comunistas te refieres? Es una histeria delirante lo que tú sufres. Están viendo rojos hasta en la sopa, será por eso que nos impides comer tranquilos' Pronto advertirás espías soviéticos en nuestro closet...-Ustedes son una generación de ignorantes y tontos útiles. Freilich (2008:51)

Extraña que luego de haber escapado de Cuba debido a su ideología socialista, discuta con su hija que comparte con sus compañeros la efervescencia que tuvo el pensamiento de izquierda en la época de Rómulo Betancourt.

En la novela muchas veces se hace énfasis en la buena acogida que tuvieron los judíos por parte del pueblo venezolano:

De eso que te está contando Amador me acuerdo porque yo era chiquito, tenía unos cinco años, pero las fiestas de pascua eran tan deliciosas allá, que mi papá prefería hacer el viaje hasta casa de su hermano en Caucagua, que pasarla aquí solitario en Caracas ...

-Y entonces nunca tuvieron dificultades por sus costumbres especiales?- Ninguna amigo mío.- Es una gran suerte, porque allá en Polonia, o en Cuba, eso no puede ser así, tan agradable... Freilich (2008:121)

Mas tarde en la novela la hija extrañará a su padre cuando ha muerto e intentará adivinar lo que él habría pensado acerca de su escritura:

Papá. Si pudieras leer este artículo, al menos vislumbrar algo de lo que pretendí expresar, ¿me hubieras condenado?, ¿aprobarías mi actitud? Tú, el hablador infatigable y chsiposo. ¿Por qué tan callado y de repente? Freilich (2008:174)

El lenguaje de Max está lleno de refranes como éste que dan idea de la densidad de la cultura judía y la larga experiencia de este pueblo para enfrentar la vida cotidiana: "Cuando la pobreza se pega de la piel no es fácil salir de ella porque tiene la cabeza gorda y entorpece la sabiduría." Freilich (2008:17) "una pelea es como la sarna, mientras más te rascas más pica." Freilich (2008:70) "iQué justo es nuestro señor, al rico le da comida y al pobre le da el apetito! Freilich" (2008:93) "Sí, algunos se han apartado de sus antiguos camaradas de pensión porque el éxito envenena incluso sin ponzoña." Freilich (2008:119) 


\section{Las confesiones de una hija}

La hija se sitúa en un momento histórico concreto en la enunciación que acaece durante la Presidencia de Rómulo Betancourt y en un hecho histórico, cuando Fidel Castro visita a Venezuela.

¡recuerda que te lo dije hoy, cuando tu simpático Fidel Castro está de visita en Caracas! Freilich (2008:51)

Ella frecuentemente se encuentra en una consulta psiquiatrica en la cual la realidad parece diluirse para hacer hincapié en que la memoria trastoca la realidad del relato, por eso la letra del himno de la Universidad Central de Venezuela no es recordada, exactamente como es:

Esta casa vence la oscuridad con su faro de luz ... Freilich (2008:11)

Y la letra del himno dice lo siguiente: " Esta casa que vence la sombra con su lumbre de fiel claridad" ("http://www.ucv.ve/fileadmin/user_upload/auditoria interna/Archivos/)

Este personaje considera que la cultura judía la ha privado de todo el tesoro cultural que la universidad le muestra, ha estado profundamente reprimida por diecisiete años, por eso consulta al psiquiatra:

Usted sabe psiquiatría y sobre todo de Sigmund Freud. Aunque no me responda, yo sé que tengo razón ¿no doctor?

¿Quién, a nombre de quiénes o de qué, va impedirme el derecho a motivar mis sentidos? ¿La Biblia? ¿El Talmud? ¿La Cábala? ¿Con qué derecho? ¿Dónde estaba yo todo el tiempo anterior a esta orgía con la verdadera cultura? Freilich (2008:42)

Frente a la fe muy fuerte del padre, la hija cuestiona todo lo que el padre cree. Circunstancia que hace la convivencia entre padre e hija muy difícil.

Sin embargo, el padre no puede vender a su hija cuando le exigen para casarse con ella una dote, costumbre ancestral que todavía se conserva en los años sesenta en la comunidad judía venezolana:

La dote era una institución muy justificable bajo cualquier análisis histórico incluido el enfoque marxista... pero estaba lejos del amor-Dime papá ¿cuánto lucro recibiste al casarte? Tu mamá con tres vestidos de algodón...,...

A veces Max podía parecer primitivo y abrupto en sus reacciones pero nunca fue un hábil mercanchifle y tampoco supo vender a la hija. Su sonrisa desbordante de picardía firmó un pacto de cómplices Freilich (2008:25)

No aceptó un matrimonio arreglado, por lo tanto la hija se mantiene con su profesión de maestra. La obra critica la forma como se ejerce el magisterio de educación secundaria en Venezuela, tanto que escribe frases como esta: 
Escribe que esta infame pedagogía conducirá al retardo mental de varias generaciones y al desastre nacional. Escribe que lean las recomendaciones de aquel maestro polaco Janusz Korczak y del no menos universal y vigente Simón Rodríguez y escribe que por favor, les hagan caso.

Será persona no grata, la piedrita en el camino, el miércoles que se atraviesa.

Sus escritos, ¿quedarían engavetados en algún archivo ministerial o fueron directo al pote de la basura?

El sistema carece de oídos para esta clase de neurastenias.

No lo creerá, pero así es, mi querido paciente doctor... Freilich (2008:81)

La novela también habla de otra maestra que expresa cuan ligados estaban los judíos al tema de la educación"Sol Corcias, señorita que sabía francés, bordaba y pintaba porque había sido maestra en Tetuán." Freilich (2008:120). Quien ... "Se iba cada mañana con un policía, de puerta en puerta, recogiendo a los niños para la escuela pues figúrate tú, que sus padres como eran todos campesinos, los querían para ayudantes en las labores del campo...-Eso se llama carácter, ¿no?.” Freilich (2008:121)

La hija no es discriminada por el hecho de ser judía, pero se siente extraña intrínsecamente en la sociedad venezolana, además de no saber practicar su política y su música.

Era una tontería de compás fijo que llamaban sabrosura, la mirada errática, un ritual a paso de sonámbula en convulsión, el monótono estar en sociedad y no ser.

Cabalgó un mar de ritmos: merengue, apambuchao de medio lao, a mí me llaman el negrito del batey, qué gente averiguá que a mí no han dao na, la burrita de Petare tiene amores... Freilich (2008:76).

La hija recuerda a su padre, su interlocutor más querido, muchas veces, pero sobre todo cuando Lech Wałęsa, aparece en el panorama mundial con su partido Solidaridad que contribuye a independizar a Polonia de la Unión Soviética entre 1980 y 1990. Al final de la novela hija y padre se reencuentran en los viejos manuscritos que le quedan como herencia para descifrar:

Con tus canciones y poemas y estos dispersos apuntes en tu amado yiddish, mientras recobro tu itinerario, busco desentrañar mi propia madeja. Tu aventura de novela ha sido vivir. Mi desventura de antinovela es aprender a convivir...Dorada cadena perpetua...

Pero y tu voz papá, ¿qué se hizo tu clara voz? Freilich (2008:191) 


\section{El regreso a Israel en Dislocaciones de Liliana Lara}

La autora destaca que la literatura Israelí es fundamentalmente una literatura escrita por emigrantes. Incluso "la Academia de la Lengua hebrea decidió otorgarle el Premio Nacional de Literatura a Fink, una escritora que solo puede ser leída en este país gracias a traducciones". Lara en Cordoliani (2013: 88)

El relato habla del proceso de integración de esta escritora-narradora Liliana Lara en esas tierras, pero además expresa una serie de conceptos importantes para el estudio de la literatura del choque cultural en el siglo XXI, motivada por tres razones básicas a nuestro entender: el viaje transitorio, la emigración o el exilio.

El primero de ellos consiste en que todo escritor es esencialmente un transterrado, fenómeno que se acentúa con el uso de las nuevas tecnologías proporcionadas por la Internet.

Para Juan José Saer todo escritor de por sí vive en una extraterritorialidad, en una tierra de nadie y tiene que hacer de ese idioma que comparte con todos los demás una lengua extranjera. Porque un verdadero escritor tiene una lengua que es propia. Lara en Cordoliani, (2013: 89)

A través de la escritura los autores pueden crear una patria ficticia, que ya no es el territorio de origen o de acogida, construidos ambos a través de la recreación que el escritor hace de estos lugares:

Para el autor (Salman Rushdie) ¿hindu?, ¿inglés?, el término "Patrias imaginarias" apela a ese espacio referencial construido con memorias y recuerdos, que es representado en muchas de las obras escritas por autores migrantes, escritores a quienes él denomina writers out-of-country. En su opinión, estos autores establecen una novedosa relación con el espacio que los rodea y con el mundo pues han perdido su habitat natural; y esta relación queda plasmada en sus obras. Lara en Cordoliani (2013: 91)

La autora en su texto Dislocación contenido en el libro Pasaje de ida. 15 escritores venezolanos en el exterior expresa también que la escritura de emigrantes no es su favorita y señala que:

La literatura abiertamente de inmigrantes no es mi favorita. Ese continuo comparar "el aquí" y el "allá", bien sea con humor o con distancia que da la ironía, me aburría- y todavía me aburre-mortalmente. Lara en Cordoliani (2013: 90)

Sin embargo, Liliana Lara piensa que esta situación es muy fructífera para el escritor, porque produce una dislocación que puede aumentar su creatividad y sensibilidad estética, ya que puede ser definida como un fenómeno que:

Para mí dislocación no es sólo un fenómeno cultural, sino también estético, cuyo alcance se patentiza tanto en esas identidades rizomáticas que la postmodernidad puso tan de moda como en aquellas estructuras y mecanismos textuales presentes en la narrativa de algunos autores migrantes. Lara en Cordoliani (2013: 92) 
A pesar de ser tan corto el relato, muestra una unión muy fuerte entre la autora y su núcleo familiar, su hija y su hijo motivan muchas de sus reflexiones acerca del fenómeno de la lengua y de la trasnsterritorialidad. Siguiendo a Hume, la autora nos demuestra que los niños tienen una percepción más fresca del mundo que la que tienen muchos adultos:

Días antes de venirnos de nuestra última estadía en Venezuela, mi hijo me dijo: "lo malo de tener dos lugares es que cuando estás aquí, extrañas allá; y cuando estás allá, extrañas aquí". Entonces le pregunté: "Y qué es lo bueno". Se quedó pensando y con su mirada profunda de cinco años me dijo: "Lo bueno es que tienes dos lugares". Lara en Cordoliani (2013: 90)

También el padre y la madre de la autora aparecen brevemente, pero no por eso menos intensamente en el relato:

De hecho, en el mapa hay un puerto en pleno río llamado - sin ir más lejos- Puerto Francés. Esa zona me apasiona y me recuerda los relatos selváticos de mi padre. Ese mapa siempre me lleva a las historias siempre esquivas y contadas a medias de mi madre. Lara en Cordoliani (2013: 92)

Esto emparenta a la autora con las historias de la diáspora judía que hemos estudiado donde la familia tiene un rol fundamental. Sin embargo ella declara que no pertenece a la religión judía. Se considera a sí misma venezolana.

Culmina este pequeño y sustancioso relato, haciendo una comparación entre el escritor transterrado y los niños:

Un escritor dislocado es un impostor, un contrabandista, un tramposo: un actor aunque muchas veces actúa muy mal. Todo escritor dislocado tiene su Brazil en cada vuelta de página. Ve pollitos en los árboles y tiene que pasar por la niñez nuevamente: una niñez lingüística y una niñez ciudadana. Lara en Cordoliani (2013: 93)

Siempre he pensado como lo hace la autora que el escritor debe conservar la niñez para poder transmitir a sus lectores su energía infantil a través de sus relatos.

\section{Conclusión}

Este trabajo confirma nuestra hipótesis de que le emigración judía, independientemente del sitio de acogida, continúa realizándose la mayor parte de las veces en familia, donde la figura de masculina del padre está muy presente. No hemos encontrado en estos relatos datos de emigración de grupos femeninos sin la presencia masculina, como ocurre con otros grupos sociales como los africanos en las novelas Rhoda (2004) de la escritora italo-somalí, Igiaba Scego, o Trois Femmes Puissantes (2009) de la escritora francesa Marie Ndiaye y en el grupo colombo-venezolano del que hablan las novelas La senda de las flores oblicuas (2005) de Eva Feld y el abrazo del Tamarindo (2008) de Milagros Socorro. 
También como los otros relatos del viaje, el exilio, y la migración, las obras estudiadas confirman la riqueza que tiene la literatura del escritor transterrado, definido entre otras cosas como un niño o un mal actor que todavía no ha podido aprenderse el libreto de la cultura a que tiene que adaptarse.

\section{Bibliografía}

ARELlANO, A. (1973). Breve historia de Venezuela. 1era edición. Caracas, Imprenta Nacional.

ALMELA, H.. (2013). "Cuatro poetas judíos". Página introductoria del Curso "Poetas Judíos" que se dictó en el edificio B'nai B'rith, Caracas, 30 de abril.

CASTRO-GÓMEZ, S. (2010). La Hybris del Punto Cero. Bogotá: Editorial Pontificia Universidad Javeriana

CHOCRÓN, S. (2012). Las mujeres de Houdini. 1era Edición, Caracas, Madrid, México, Bruguera.

CORDOLIANI, S. (2013). Pasaje de ida. Caracas: Editorial Alfa.

FEBRES, L.. Compiladora. (2008). La mirada femenina desde la diversidad cultural de las Américas: Una muestra de su novelística de los años sesenta hasta hoy. 1 era edición, Caracas, Universidad Metropolitana.

FEBRES, L.(2012) "La diversidad cultural de la novela femenina venezolana en la primera década del siglo XXI" En: Calderilla Domínguez, David. (cord.) (2013). El EEES como plataforma de innovación universitaria. Madrid: Visión Libros, p.107-132.

FEBRES, L. Compiladora.(2013). La mirada femenina desde la diversidad cultural: Una muestra de su novelística de los años noventa hasta hoy. (Tomo II). 1era edición, Caracas, Universidad Metropolitana.

FREILICH, A. (2008). Claper el marchante. Caracas: bid \& co. editor c.a. 4ta edición.

LERNER, E. (1976). Vida con Mamá. Obra Teatral. 1era. Edición, Monte Ávila Editores. Caracas.

PORZECANSKI, T. (1995). Perfumes de Cartago. 4ta Edición, Montevideo, Trilce.

SHARONAH, F.; KATZ, E.; KISILEVSKI, M.;KOHAN, A.; VILLA, D. (2003). El judaísmo y la mujer. 1era Edición, Buenos Aires, Fundación Alianza Cultural Hebrea.

BROOKS B. I., (2011). "Israel, los indignados y la política genocida-expansionista. ¿crisis, cambio o continuidad de un sistema?". Humania del Sur. Revista de Estudios Latinoamericanos, Africanos y Asiáticos. Universidad de los Andes Venezuela, Centro de Estudios de África y Asia, Mérida, Venezuela, Julio-Diciembre, Año $6-\mathrm{N}^{\circ} 11$. 


\subsection{Publicaciones en la web}

AGOSIN, M. (1999). The House of Memory: Stories by Jewish Women Writers of Latin America (The Helen Rose Scheuer Jewish Women's Series) http:// books.google.es/books?id=iZABYDlV598C\&pg=PA52\&lpg=PA52\&dq=Marcus + Sagalij\&source $=$ bl\&ots $=4 \mathrm{mVxerGH}+\mathrm{W} \&$ sig $=$ GkC55h7ayzy $31 \mathrm{cWvQKZ}$ JnhO-clE\&hl=es-419\&sa $=$ X\&ei $=3$ zDgUeRi0t3gA77DgfAK\&ved=0CC0Q6AEwAA\# $\mathrm{v}=$ onepage $\& \mathrm{q}=$ Marcus $\% 20$ Sagalij $\& \mathrm{f}=$ false. [Recuperado el 11 de julio de 2013]

http://www.avempace.com/personal/jose-antonio-garcia-fernandez [Recuperado el 26 de julio de 2013]

Lara, L. http://lilianalara.wordpress.com/Marzo3, 2013. [Recuperado el 10-10-2013]

Lara,L "http://www.ucv.ve/fileadmin/user upload/auditoria interna/Archivos/Documentacion_-_Publicaciones/Himno_de_la_Universidad_Central_de_Venezuela. pdf [Recuperado el 24 de septiembre de 2013]

\section{La autora}

En 1977 egresa como Licenciado en Letras de laUCAB En 1987 se gradúa de Magister en Literatura Latinoamericana Contemporánea en la USB, recibiendo Mención de Honor por su tesis, Pedro Henríquez Ureña: Crítico de América publicada por La Casa de Bello. Libro reimpreso en Santo Domingo República Dominicana en 2010.

En 1990 ganadora de la beca Fulbright, investigación en Yale University. En noviembre de 2000 recibe el título de Doctor en Historia, Suma Cum Laude UCAB. El trabajo de tesis publicado por la UNIMET con el título La Historia en Mario Briceño-Iragorry en enero de 2002 .Su últimas compilaciones llevan los títulos A Los Amigos invisibles. Visiones de Arturo Uslar Pietri (2006), La mirada femenina desde la diversidad cultural de las Américas(2008 y 2013) y La religiosidad en el siglo XVIII venezolano en el (2010). 